\title{
O Fervo, a Diversidade Sexual e de Gênero e a Pedagogia da Prevenção
}

\author{
Vinicius Alves ${ }^{1}$ \\ "eu tenho pressa e \\ eu quero ir pra rua \\ quero ganhar a luta que eu travei

Resumo: Este artigo apresenta um diálogo entre a pesquisa em HIV/AIDS e o campo teórico-político da diversidade sexual e de gênero. Utilizo como elemento para tal reflexão o estudo etnográfico realizado para a conclusão do Bacharel em Estudos de Gênero e Diversidade denominado "Em Defesa do Fervo: visões etnográficas sobre o surgimento da produção de cuidados no contexto de festas urbanas em Salvador-Bahia Brasil". Essa contribuição é relevante para a recomposição de estudos e lutas LGBTI+ no país e para o campo histórico que construiu os estudos e respostas à epidemia de AIDS no final dos anos 80 e início dos anos 90 (especialmente sua potente corrente comunitária). No entanto, acredito que essa reaproximação deve ocorrer com a atualização dos nossos olhos e o reconhecimento de novas formas de organização política e protesto social. Eu defendo o fervo como um contexto privilegiado para isso, porque é realizado por jovens, negros, mulheres e pessoas LGBT da periferia. $\mathrm{O}$ grupo de coletivos que organiza partidos urbanos politicamente engajados (que eu chamo de Fervo), hoje nos mostra um potencial organizacional e emergente (no sentido de urgência e emergência) de zelador. Argumentamos que seu reconhecimento (deles) pode ajudar no processo de reflexão e oxigenação de nossas estratégias no movimento LGBTI+ no Brasil. Na mesma linha, eles também podem fortalecer o que foi apontado nas recentes produções da ABIA, e seu CEO Richard Parker, sobre a chamada "pedagogia da prevenção" - um novo paradigma social proposto pela entidade para organizar a resposta à epidemia. Propomos aqui a abertura de algumas reflexões envolvendo a ebulição, a diversidade sexual e de gênero e a pedagogia da prevenção.

Palavras-chave: Festa; Cuidado; Lutas LGBTQI+; HIV/AIDS; Diversidade Sexual e de Gênero.

\footnotetext{
${ }^{1}$ Bacharel em Estudos de Gênero e Diversidade pela Faculdade de Filosofia e Ciências Humanas da Universidade Federal da Bahia (FFCH-UFBA). Atua como coordenador geral da Coordenação de Políticas LGBT do governo do estado da Bahia. E-mail: viniciusalves.lgbt2@gmail.com
} Vol. 01, N. 04, Out. - Dez., 2018 - www.revistas.unilab.edu.br/index.php/rebeh 


\section{Introdução}

O presente artigo $^{2}$ apresenta-se com a proposta de promover um diálogo entre as pesquisas sobre festas, os estudos de HIV/AIDS e o campo teórico-político da diversidade sexual e de gênero. Entendo ${ }^{3}$ ser relevante contribuir para o processo de recomposição das lutas LGBT no país com o campo que construiu as respostas à epidemia de AIDS no final dos anos 1980 e início dos anos 1990 - sobretudo na sua dimensão comunitária. Ao mesmo tempo, considero importante atualizar a compreensão de ambos os campos sobre o uso das festas, seja sobre o seu emergente papel como produtora de cuidado no campo da prevenção combinada ao HIV ou mesmo da aproximação das tradicionais expressões organizativas dessas lutas com novas formas de participação democrática.

Apresento-me aqui como um concluinte do bacharelado em estudos de gênero e diversidade da Universidade Federal da Bahia. Também sou um jovem ${ }^{4}$ (e fervido) militante LGBT brasileiro, orgânico nos últimos 11 anos das fileiras do movimento LGBT em nível local ${ }^{5}$ e em nível nacional ${ }^{6}$. Recorro no campo de estudos do HIV/AIDS, às produções da ABIA e de seu atual diretor-presidente Richard Parker, sobre a chamada "pedagogia da prevenção".

A ABIA é fundada em 1986 com o nítido objetivo de democratizar as informações sobre a epidemia de HIV/AIDS e inspirou boa parte da opinião das primeiras organizações comunitárias do país. O GAPA-Bahia, fundado em 1988, nasce também como um difusor das informações que se tinha disponível sobre a epidemia,

\footnotetext{
${ }^{2}$ Agradeço à Tatiana Lionço, Thiago Coacci e Mario Carvalho pelo aceite para publicação nesse dossiê, assim como pelos valorosos comentários feitos a primeira versão deste texto.

${ }^{3}$ Este texto é fruto de conexões entre academia, militância e cuidados comunitários em saúde. O uso do "eu" se remete as minhas reflexões presentes em meu trabalho de conclusão de curso, já o uso do "nós" se remete às coletividades envolvidas nas conexões entre tais processos.

${ }^{4}$ Tenho 29 anos enquanto escrevo este artigo.

${ }^{5}$ Na Bahia, atuando no Coletivo Kiu! pela Diversidade Sexual e de Gênero, na Associação Beco das Cores - Educação, Cultura e Cidadania LGBT e no Fórum Baiano LGBT, além da militância partidária na Esquerda Popular Socialista, tendência interna do Partido dos Trabalhadores. Desde 2015 até o fechamento deste artigo estou como Coordenador Geral da Coordenação de Políticas LGBT no Governo do Estado da Bahia.

${ }^{6}$ Sou filiado a organizações de base, atuo como militante e, no último período, fui Secretário Nacional de Relação com os Movimentos Sociais da Associação Brasileira de Lésbicas, Gays, Bissexuais, Travestis, Transexuais e Intersexos - ABGLT. Participei da coordenação política e construção das 5 edições da Marcha Nacional Contra a Homofobia e representei a ABGLT durante duas gestões dos Conselhos Nacionais LGBT (CNCD-LGBT) e de Juventude (CONJUVE).
} Vol. 01, N. 04, Out. - Dez., 2018 -www.revistas.unilab.edu.br/index.php/rebeh 
tendo a ABIA como referência daquele momento. Por isso, o contato com tais produções foi importante para o desenvolvimento de um estudo etnográfico que identificou a emergência (no sentido da urgência e do surgimento) da produção de cuidado no contexto de festas urbanas politicamente engajadas em Salvador (especificamente as festas Afrobapho, Batekoo e TOMBO), realizado por mim como trabalho de conclusão de curso, assim como para pensar os pontos de reconexão de tais campos e lutas.

Neste momento de golpe parlamentar-jurídico-midiático-militar nas instituições democráticas do país, que restringe as políticas sociais e torna ainda mais vulnerável e precária a vida das pessoas, - assim como, mais recentemente, de vitória eleitoral de uma candidatura cuja plataforma política representa uma agenda regressiva do ponto de vista dos direitos civis - também experimentamos um avanço entre adolescentes-jovens (1519 anos) e jovens-jovens (19-24 anos) da epidemia de HIV/AIDS (BRASIL, 2017).

Considerei ser oportuno realizar um estudo que buscasse (re)aproximar a construção de respostas comunitárias dos locais de sociabilidade juvenil. Recortei, dentre os locais, as festas urbanas que tinham na organização e participação um protagonismo de jovens negras(os), mulheres e LGBT, de periferia. As localizei em torno do que identifiquei, a partir da imersão em diferentes cenas, como sendo o fervo.

Propus uma defesa do fervo ${ }^{7}$, considerando e em homenagem ao que foi feito por Edward MacRae (1983) em um outro momento da história na defesa do gueto. MacRae nos demonstra a potência que os deslocamentos de homossexuais no território do centro de São Paulo tiveram na construção da identidade homossexual no final dos anos 1970. Ao mesmo tempo ele nos mostra como tal fator foi determinante para a organização dos primeiros grupos de homossexuais e também da resposta comunitária a epidemia do HIV que surgia pouco tempo depois.

Produzimos, com os devidos limites e diferenças de pontos de partida e chegada (assim como de acúmulo e referência histórica) com o estudo de MacRae, uma pesquisaação que tinha uma consideração comum com o que chamamos de olhar macraeano: o reconhecimento. MacRae reconheceu nos anos 1970 um elemento forte para identificação das pessoas como sujeitas(os) homossexuais: o gueto. No mesmo caminho,

7 "Em defesa do Fervo: olhares etnográficos sobre a emergência do cuidado no contexto de festas urbanas em Salvador-Bahia-Brasil" é o título do meu trabalho de conclusão de curso do Bacharelado em Estudos de Gênero e Diversidade, do Departamento de Estudos de Gênero e Feminismos da Universidade Federal da Bahia, apresentado e aprovado em setembro de 2017.

Vol. 01, N. 04, Out. - Dez., 2018 -www.revistas.unilab.edu.br/index.php/rebeh 
buscamos em 2016, reconhecer o que é posto à margem ou de maneira contingente em parte das nossas considerações organizativas (das esquerdas ou do movimento social LGBT mais tradicional) ainda hoje, mas que segue acontecendo e correndo de maneira mais aproximada na vida cotidiana da sociedade em geral, nos seus deslocamentos, na construção de diferentes sociabilidades, referências, trocas, presenças e pertenças: $o$ fervo. Em outras palavras, seja nos anos 1970 ou em 2016, ambos buscamos reconhecer elementos determinantes da organização da vida social, mas sobretudo, da afirmação política e cidadã de identidades, expressões e experimentações sexuais e de gênero. Naquele momento fora o gueto, hoje, proponho o fervo.

Identifico o fervo, portanto, como sendo um emergente conjunto de deslocamentos e de novas formas de participação democrática produzidas em torno da organização de festividades urbanas politicamente engajadas. Destaco aqui as festividades que são protagonizadas por jovens negras(os), mulheres e LGBT, de periferia por um necessário reconhecimento sobre uma cena protagonizada pelas sujeitas mais subalternizadas nos processos interseccionados de produção de desigualdades sociais. "O fervo é protesto”, afirma Rico Dalasam, primeiro rapper negro e gay da periferia de São Paulo ${ }^{8}$. Sua frase foi um disparador para costurar o estudo como uma forma de aproximação e reconhecimento do que estava por detrás desse termo - ou melhor, de quem estava protagonizando o uso desse termo como forma de expressar o seu protesto social e organizar uma nova forma de luta política. Pude identificar, a partir daí, possíveis colaboradoras e mesmo quem se via e se colocava em luta a partir da organização e/ou participação em festas que traziam uma narrativa do fervo e reforçavam a ideia de estarem "fervendo" como forma de lutar e protestar por algo.

Considero aqui como politicamente engajadas festividades que trazem, desde sua chamada, até o posicionamento das participantes e das organizadoras, elementos em relação a diferentes agendas de lutas sociais (presentes em todo processo de préprodução, produção e pós-produção). Festas como a Batekoo, onde desenvolvi parte da imersão do trabalho de campo e que está presente em mais de 5 capitais do país organizando um público de jovens negras(os), mulheres e LGBT de periferia (disputando espaço diretamente com o circuito do mercado GLS/pink-money

\footnotetext{
${ }^{8}$ A entrevista citada com Rico Dalasam foi publicada no dia 08 de janeiro de 2015 no portal SPRESSOSP. Disponível em < http://spressosp.com.br/2015/01/08/o-fervo-e-protesto/ >. Acesso dia 23 de maio de 2016.
}

Vol. 01, N. 04, Out. - Dez., 2018 - www.revistas.unilab.edu.br/index.php/rebeh 
convencional), trazem a seguinte mensagem nos eventos que marcam sua divulgação: "Liberdade corporal, liberdade sexual, estética negra, empoderamento, crespo, suor, representatividade, ocupação preta, proibidão. Festa de preto."; ou mesmo o registro em algumas de suas edições de que "transexuais e travestis entram VIP"; e sempre em todas a afirmação de que "não será tolerada nenhuma forma de opressão".

Por essas frases, percebemos uma narrativa afirmativa e reparatória, que desloca os reconhecimentos sobre uma série de cidadanias subalternizadas e realça as identificações coletivas. Ao mesmo tempo elas nos pareceram defender aí tantos sonhos e lutas historicamente travadas por um conjunto de pessoas e organizações sociais consideradas como "mais tradicionais". Apostamos, por isso, que estava aí a importância em aproximar tais coletivos e coletividades da reflexão sobre as novas estratégias de luta dos movimentos LGBT no Brasil, sobretudo na aproximação com a comemoração de seus 40 anos de existência mais orgânica - esforço deste artigo.

Consideramos que essa potência, identificada pelo estudo etnográfico que desenvolvi, se deu devido à demonstrada capacidade organizativa de tais produções, onde o engajamento político na questão racial, sexual, de classe e gênero foram determinantes importantes para aglutinar o seu público e construir a sua rede de cuidado e afeto. Além disso, tais produções têm conseguido criar possibilidades de alianças com organizações sociais mais históricas. Exemplo disso pode ser visto na parceria para realização do Festival I.D. - Identidade e Diversidade (realizado em setembro de 2018 em Salvador, antecedendo as atividades da Parada do Orgulho LGBT da cidade). A Batekoo, Afrobapho, Coletividade Námíbíà e outros coletivos de jovens fervidas, aliaram-se a $\mathrm{ABGLT}^{9}$ e a $\mathrm{ANTRA}^{10}$, servindo para aproximar as duas maiores e mais tradicionais organizações LGBT e Trans* do país com uma geração política de jovens (por que não?) lutadoras. Na próxima seção deste artigo busco aprofundar alguns pontos sobre o estudo que serviram de contribuição para as reflexões seguintes sobre tais possibilidades de aliança e estratégias de luta LGBT no Brasil e, mais a frente, com a agenda da pedagogia da prevenção.

\footnotetext{
${ }^{9}$ ABGLT é a sigla da Associação Brasileira de Lésbicas, Gays, Bissexuais, Travestis, Transexuais e Intersexos. Fundada em 1995, a ABGLT é a maior organização LGBT da América Latina, com mais de 300 organizações afiliadas em todo território nacional brasileiro.

${ }^{10}$ ANTRA é a sigla da Associação Nacional de Travesti e Transexuais. Fundada em dezembro de 2000, ela conta hoje com mais de 150 organizações afiliadas em todo território nacional.
}

Vol. 01, N. 04, Out. - Dez., 2018 - www.revistas.unilab.edu.br/index.php/rebeh 


\section{O Fervo - um estudo etnográfico e um convite a reflexão sobre nossas estratégias de luta interseccional LGBT no Brasil \\ "não é normal querer o novo e ser igual..." \\ (Demodê - Diego Moraes, 2015)}

Para fins de análise, delimitamos o campo ao fervo produzido com um protagonismo e participação de jovens negras(os), mulheres e LGBT de periferia representado pelas festas e coletivos Afrobapho, Batekoo e TOMBO em Salvador. Essas festas se constituem em poderosas redes de afeto e cuidado, resinificando as dimensões da organização e da participação, e sendo o elo de ligação, formação e troca de uma geração política de jovens ${ }^{11}$, como eu.

O fervo atravessou a minha história de diferentes maneiras ao longo dos meus 10 anos de vida universitária. As diferentes experiências envolvendo festa e política no movimento estudantil geral ou no universitário pela diversidade sexual (sobretudo a partir do ENUDS ${ }^{12}$ ) me permitiram participar e organizar muitas festividades - cujo fim era produzir um engajamento ou participação política das pessoas que mobilizávamos para nossas atividades/encontros/congressos/conferências/etc. A chamada "cultural" dos encontros, seminários, semanas e rodas que sempre organizamos tinham, ao fim, uma função também política de possibilitar os nossos encontros, a nossa sociabilidade, a nossa convivência e com ela o estimulo a articulação de nossos sonhos e planos.

Participei e organizei festividades em torno do ENUDS e das atividades da $\mathrm{ABGLT}^{13}$, assim como, localmente, junto com a militância no Coletivo Kiu! de Diversidade Sexual e de Gênero e do Diretório Central dos Estudantes (DCE) da UFBA. Também fiz parte da organização de festividades vinculadas ao movimento antiproibicionista local. Aqui cabe destacar que entendemos, para fins analíticos, que todas somos, em algum grau, pessoas que usam drogas. Contudo, a proibição fez com

\footnotetext{
${ }^{11}$ Tomamos aqui como referência etária para o termo jovem o que é reconhecido no Estatuto da Juventude como sendo a pessoa com idade entre 15-29anos.

${ }^{12}$ O ENUDS é a sigla do Encontro Nacional Universitário pela/para/de/sobre Diversidade Sexual, até ano passado realizado como ENUDSG, onde o G representa a composição da Diversidade Sexual com a ideia de identificarmos este campo com o termo Diversidade Sexual e de Gênero.

${ }^{13}$ Participei da organização das primeiras edições das Marchas Nacionais Contra Homofobia, realizadas pela ABGLT em Brasília a partir de 2010. Era membro da Comissão Política da Juventude da ABGLT e realizamos em parceria com o DCE da UnB as primeiras edições do UnB Fora do Armário, com debates durante o dia e festas ao longo da noite que lotaram os corredores da universidade e levaram muita gente a compor as fileiras das Marchas na Capital Federal.
}

Vol. 01, N. 04, Out. - Dez., 2018 - www.revistas.unilab.edu.br/index.php/rebeh 
que ao longo da história algumas práticas e usos passassem a ser vistas de maneira estigmatizada e, por isso, criminalizadas. Isso passou a ser organizado como uma ação sistêmica do que alguns estudos e estudiosas/os sobre drogas vêm conceituando como sendo o proibicionismo.

Ele (o proibicionismo) poderia ser entendido como um sistema estrutural que estabelece de maneira desigual o local das pessoas que usam drogas na sociedade e na relação entre si. Seus efeitos se relacionam fortalecendo e sendo fortalecido por outras relações/sistemas de opressão e determinação desigual do poder e, com eles, das oportunidades de vida. Ou, como bem colocado pelo pesquisador, advogado e ativista Antônio Carlos Ribeiro Júnior (2017, p. 77): “O proibicionismo contemporâneo é utilizado para legitimar a Guerra às Drogas, que não é um embate político entre nações, mas movido contra determinadas pessoas e grupos eleitos como inimigos."

Acreditamos que embora os diferentes usos e rituais de/com drogas atravessem a história da humanidade de muito tempo, é mais recente tanto sua proibição quanto a busca pela compreensão dos efeitos que esta proibição teve e tem na vida em sociedade. Ribeiro Júnior nos fala que

\footnotetext{
Não é possível determinar qual foi a primeira vez que ocorreu a proibição ao consumo de substâncias que causem efeitos psicoativos. Sabe-se que em diversos períodos e em diferentes sociedades houve a limitação ao uso de determinadas drogas. Contudo, é a partir do início do século XX que as drogas passam a ser alvo de políticas públicas. As drogas são divididas pelo estado em permitidas e proibidas. Assim, a gestão dos processos de produção, de distribuição e de consumo destas substâncias pode ser de regulamentação ou de criminalização. O critério utilizado para inseri-las em um grupo ou no outro é o fato de determinada droga compor o conjunto cultural de certos grupos sociais ou étnicos. Não se trata de criminalização das substâncias, mas das pessoas que fazem uso destas substâncias. (RIBEIRO Jr., 2017; p. 77)
}

Os estudos de Ribeiro Júnior (2017), assim como nossa atuação mais orgânica junto a institucionalização mais recente movimento antiprobicionista em Salvador, no Brasil e na América Latina, nos fizeram refletir sobre como era importante transpor tais questões à arena acadêmica feminista interseccional e interliga-los a partir daí a um processo de pesquisa. O antiproibicionismo, portanto, na sua dimensão sociológica, aparece como a antítese do proibicionismo. Ele é a proposta antagônica, de ruptura e (re)construção de um novo paradigma cultural sobre o uso de drogas. O projeto antiproibicionista opera desconstruindo e superando o contexto proibicionista, revelando as desigualdades estabelecidas por este entre os usos de drogas e produzindo, assim,

Vol. 01, N. 04, Out. - Dez., 2018 - www.revistas.unilab.edu.br/index.php/rebeh 
possibilidades para refletir alternativas de cuidado à vida das pessoas que usam drogas, ou seja, de toda sociedade. O antiproibicionismo é, como apontado por Ribeiro Júnior (2017), o projeto, mas também a perspectiva e a trincheira de luta que reposiciona a(s) pessoa(s) que usa(m) drogas como o ponto de partida para qualquer apontamento ou (sempre relativa e contextual) solução dos problemas criados em torno da drogadição (dimensão relacional que revela a desigualdade estabelecida entre as pessoas que usam drogas).

Os contatos com as pessoas, coletivos e festas do estudo sobre o fervo, permitiram-me olhar outros elementos que até então seguiam encobertos ou eram apresentados, nas principais escolas que recorri para fundamentar o estudo, de uma maneira afastada do que encontrei em campo. E, aqui cabe dizer que, os estudos feministas, LGBT, antiproibicionistas e de HIV/AIDS falam muito pouco ou quase nada sobre o uso que as festividades urbanas podem ter como ferramenta de organização e protesto social, assim como de produção de cuidado ou da sua contribuição para a organização de identidades cidadãs nas democracias moderno-ocidentais.

Os estudos mais próximos que encontrei não têm tradução em português e são do australiano Kane Race ${ }^{14}$ (2009; 2011). Race no artigo "Party Animals: The significance of drug practices in the materialization of urban gay identity" (2011) nos faz compreender que a "emergência da identidade gay contemporânea é impossível [de ser apreendida] sem considerar a história das festas" (RACE, 2011, p. 35, tradução nossa). Com mais fôlego, no seu livro "Pleasure Consuming Medicine: The Queer Politics of Drugs" (2009) ele traz uma posição crítica sobre o que chama de "propriedade do consumo", assim como sobre o papel que as atuais regulações sobre drogas ilícitas cumprem na estruturação de discursos morais em torno de tais consumos (identificados por ele como um outro determinante da construção da identidade gay urbana - a drogadição, o uso de drogas lícitas e ilícitas para buscar ou ter práticas sexuais e/ou prazer).

Para Race $(2009 ; 2011)$ o controle sobre o "consumo de prazer", regulado sobretudo pelo que é considerado, produzido, comercializado e consumido como drogas lícitas ou ilícitas, tornou-se um dispositivo sofisticado de ação do Estado neoliberal sobre a organização da vida. Ele questiona o uso dado ao conceito de "vida saudável" -

14 Kane Race é um pesquisador australiano do departamento de Gênero e Estudos Culturais da Universidade de Sydney. Ele é assumidamente uma pessoa vivendo com HIV/AIDS.

Vol. 01, N. 04, Out. - Dez., 2018 - www.revistas.unilab.edu.br/index.php/rebeh 
identificado como sendo exacerbadamente atrelado ao estímulo para o consumo de medicamentos e substâncias produzidas pela indústria de fármacos ou de estética (como shakes e outros produtos que prometem um corpo normatizado, magro, sarado, sem pelos ou gordura - ou seja, “saudável”). Ele questiona ainda em seus estudos a liberdade e os incentivos públicos e privados que tais indústrias, farmacêutica e de estética, têm para inserir novas substâncias e drogas no cotidiano da vida das pessoas. E que, por isso (mas também pelo uso dado ao consumo de substâncias consideradas ilícitas para buscar ou ter práticas sexuais e prazer), as festas e o consumo de drogas (lícitas e ilícitas) são elementos a serem considerados na observação da construção da identidade gay contemporânea.

Alguns estudos sobre "drogas e festas" nos auxiliaram bastante na construção das estratégias de aproximação e interlocução do estudo realizado sobre o fervo. Alguns deles traziam reflexões sobre as culturas de uso de drogas e a produção de cuidado em festas e festivais de música eletrônica (GUIMARÃES; MACRAE; ALVES, 2012), as chamadas raves, que no geral não são caracterizados como festividades urbanas por ocorrerem mais afastadas dos centros urbanos (em chácaras, sítios ou fazendas das zonas mais rurais). Identificamos que tais estudos nos ajudariam na aproximação com a cena das festas e festivais a partir do acúmulo sobre a ética e da técnica da Redução de Danos (RD) nesses contextos.

O uso dos espaços de sociabilidade proporcionados pelas festas e festivais, incluindo aí as primeiras raves, como forma de contestar a ordem social marcou a contracultura na história moderna ocidental por seu caráter libertário. O uso de drogas como contracultura, assim como ela própria enquanto movimento, encontrou na música (sobretudo no rock e na eletrônica) uma forma e um método fundamental de aglutinar pessoas, alcançando nos anos 1960 uma juventude de camadas médias urbanas, sobretudo universitária (PEREIRA, 1980).

Tais expressões de festividades e locais, as raves, são majoritariamente frequentados e protagonizados por pessoas privilegiadas(os) econômica (ricos), racial (brancos) e sexualmente (heterossexuais). Este caminho, embora importante para o desenvolvimento de referências, não foi o mesmo escolhido por nós no estudo sobre o fervo por considerar que o vetor das novas infecções ao HIV/AIDS alcança pessoas em

Vol. 01, N. 04, Out. - Dez., 2018 - www.revistas.unilab.edu.br/index.php/rebeh 
maior vulnerabilidade social, ocasionada, dentre outras coisas, em função das desigualdades sociais.

Vale destacar, ainda, que esses estudos já nos sugeriam que tais espaços seriam um contexto de risco para atividades sexuais desprotegidas (GUIMARÃES; MACRAE; ALVES, 2012). Acreditamos que a partir daí e da consideração sobre o atual cenário epidemiológico brasileiro (com um vetor de crescimento entre jovens, gays e negros autodenominados pardos no Boletim Epidemiológico ${ }^{15}$ ) era preciso acumular também experiências etnográficas no sentido de festividades urbanas que trouxessem como protagonistas da sua organização e maioria do seu público jovens negras(os), mulheres e LGBT, de periferia, sobretudo com idade entre 20-24 anos - convocando assim outros determinantes sociais para qualificar uma reflexão sobre a produção de cuidado e as possibilidades de construir novas estratégias comunitárias pelo fim da epidemia do HIV/AIDS entre esta população.

Aproximamos, no diálogo da pesquisa com esses coletivos de festas, uma proposta de organização da resposta comunitária a epidemia do HIV/AIDS entre jovens. Trouxemos como aliadas as formulações no campo da prevenção ao HIV/AIDS e Infecções Sexualmente Transmissíveis (ISTs), da redução de danos, do antiprobicionismo, do feminismo e da diversidade sexual e de gênero - como elementos reconhecidos por elas(eles), ou novos ou que eram pouco apreendidos pelos coletivos e coletividades organizadoras das festas colaboradoras.

Algumas questões me despertaram para a importância de tornar tais festividades objeto de uma observação participante e investigação científica. Uma delas foi ler, ver e ouvir de tantas pessoas que nós, jovens, "perdemos o medo da AIDS" ou que "não temos mais medo da morte" e de que só queremos saber de "festa, sexo e drogas" ou de "ferver". Embora não neguemos alguns deles (com um sentido oposto de quem os professa tentando reduzir as nossas potencialidades), tais afirmações sempre me pareceram um mantenedor de um pânico moral contra nós - uma nova geração política que retoma a agenda da liberdade sexual e de gênero ao centro da discussão e da organização de nossa identidade sexual e de gênero, do reconhecimento reparatório e afirmativo de nossas pertenças econômicas, raciais e étnicas, da valorização das culturas,

15 Tomamos como referência para o estudo e para este artigo os dados dos Boletins Epidemiológicos HIV/AIDS dos anos de 2013, 2014, 2015 e 2016, disponível em < http://www.aids.gov.br/pt-br/centraisde-conteudos/boletins-epidemiologicos-vertical > acessado em 28 de novembro de 2018.

Vol. 01, N. 04, Out. - Dez., 2018 - www.revistas.unilab.edu.br/index.php/rebeh 
comportamentos, estéticas e costumes ancestrais, que foram encobertos pelo processo de escravização, colonização e modernidade. Nos pareceu recorrente a investida moralista, assim como nos parecia ser importante identificar e reconhecer nossos polos de resistência (afinal, eles virão, como sempre vieram, e nós iremos!).

Nesse processo de identificação da nossa resistência encontramos o fervo e as fervidas e nos reconhecemos no seu potente processo e fundamento, que nos inspiraram a uma etnografia em sua defesa (SILVA, 2018). Não que elas e eles precisem de uma formulação acadêmica sobre as suas vivência e experiências para serem legitimadas. Contudo, sabemos que no processo histórico, o reconhecimento da organização de setores sociais, foi determinante na luta de novas cidadanias e para a disputa das reparações sociais e históricas.

Acreditamos que o estudo pôde ser oportuno para auxiliar no processo de (re)construção de pontes entre a diversidade sexual e de gênero e as formulações que apontam a necessidade de um novo momento na resposta à epidemia em nível local e global. Da mesma maneira, acreditamos que foi possível aproximar o reconhecimento de novas formas de participação democrática, protagonizadas por jovens negras(os), mulheres e LGBT de periferia, da organização social e institucional dos movimentos LGBT contribuindo para refletir suas estratégias de luta.

A defesa do fervo foi responsável ainda por nos aproximar, nós jovens fervidas de Salvador, de um conjunto de reflexões sobre o atual momento da epidemia e, sobretudo, da fragilidade que passamos na dimensão da prevenção e das respostas comunitárias. Buscamos reunir no tópico seguinte algumas opiniões e argumentos (construídas ao longo do processo de pesquisa-ação), que servem como base para nos colocar dentro das discussões sobre as respostas à epidemia de HIV/AIDS - ou, como propomos aqui, na abertura de uma aliança do fervo e da diversidade sexual e de gênero com o fortalecimento da Pedagogia da Prevenção e das novas respostas comunitárias à epidemia do HIV/AIDS.

\section{A Diversidade Sexual e de Gênero e a Pedagogia da Prevenção - do que estamos falando?}

"entrega o seu corpo somente a quem possa carregar"

Serei(A) - Linn da Quebrada

Vol. 01, N. 04, Out. - Dez., 2018 - www.revistas.unilab.edu.br/index.php/rebeh 
Nos aproximamos aqui daquelas(es) cujos entendimentos sobre o avanço das novas infecções pelo HIV (e mortes por AIDS) não partem apenas de uma compreensão biológica da epidemia. Acreditamos, portanto, que a epidemia do HIV/AIDS é socialmente determinada pelo conjunto de desigualdades sociais estruturantes das sociedades modernas ocidentais (DUSSEL, 1992). Como nos mostra Bastos e Szwarcwald (2000) ao citar a compreensão de Paul Farmer (1996, 1997) sobre ecologia social das doenças infecciosas:

Farmer tem incorporado aos modernos estudos acerca da ecologia das doenças infecciosas uma dimensão de ecologia social, ou seja, compreende ele a emergência, reemergência e disseminação seletiva dos patógenos como não apenas tributária da biologia evolucionista e da ecologia dos agentes infecciosos, mas também dos impactos da iniquidade social e da violência estrutural, esta última numa acepção bastante ampla (que incorpora não apenas a violência em um sentido específico mas também quaisquer violações dos direitos humanos). (BASTOS; SZWARCWALD, 2000, p. 9)

Esse reconhecimento de Farmer (1996, 1997), trazido nas formulações de Bastos e Szwarcwald (2000) nos anos 2000, a uma dimensão social da epidemia, sedimentou, em alguma medida, o caminho para o reconhecimento de identidades políticas nos canais de interação sócio estatal. Explico: para muitas de nós LGBT (com destaque a população gay, de travestis e mulheres transexuais), o diálogo mais orgânico com o Estado e o desenvolvimento de políticas públicas que considerassem (muitas vezes à sua maneira limitada e normatizada) nossa "especificidade", dar-se sobremaneira por conta do avanço de uma epidemia e uma doença entre práticas sexuais que faziam (fazem) parte do nosso cotidiano (mas não só, embora sejam consideradas como exclusividade nossa), e que fizeram (e seguem fazendo) muitas de nós adoecer ou morrer. É neste cenário que avança a pecha de que somos nós a própria doença encarnada e esculpida, e isso tem como consequência direta o aumento do estigma e preconceito contra as pessoas LGBT.

Com contornos cada vez mais visíveis e públicos, a violência contra nossa população, desde o início da epidemia, foi ganhando colunas sociais, atenção de políticos e cientistas, até ganhar os púlpitos de alguns setores e cultos religiosos hoje que se organizam em torno dos discursos de ódio contra nós. Tais violências operam pela condenação e controle mais forte de nossas vivências e práticas, dos nossos espaços, dos nossos modos de vida e comportamento - associados a contaminação por

Vol. 01, N. 04, Out. - Dez., 2018 -www.revistas.unilab.edu.br/index.php/rebeh 
uma doença que, no momento de sua descoberta, levava à morte sem que se tivesse muita informação (até no meio médico e científico) das causas que levavam a isso.

Apesar de tanto não e tanta dor que nos invade nós fizemos dos nossos espaços de sociabilidade (com todos os limites para acessá-los e/ou mantê-los em funcionamento), das nossas representações públicas e artísticas, dos nossos deslocamentos pelos grandes centros urbanos, um potente e articulado circuito de vivências que resistiram e foram determinantes para reafirmar as pertenças de nossas identidades sexuais e de gênero e, mais a frente, para organizar diferentes expressões (até hoje) do nosso movimento e luta por cidadania.

As ideias em torno da "liberdade sexual" que se apostava no momento de abertura democrática no país, encontrava nos Dzi Croquettes, Caetano, Gil, Ney, Cazuza, nos bares, boates, saunas, nas ruas, nos banheiros, no nosso desbunde organizado, nas nossas respeitáveis militantes, nas movimentações feministas e pelos direitos das mulheres, na Soul Music e toda movimentação em torno da identidade do “negro livre”, nas indispensáveis bichas loucas, no gueto (MACRAE, 1983) e em tantas outras referências criadas por nós, a força social da nossa agenda em surgimento mais orgânico e contestatório.

Foram elas determinantes para constituição do sujeito homossexual no Brasil num primeiro momento e, mais à frente, das diferentes identidades sexuais e de gênero que são utilizadas até hoje como forma de manter e disputar a garantia de direitos e o diálogo institucional em torno de nossas demandas e necessidades: as conhecidas LGBT ou mais recentemente ainda $\mathrm{LGBTQI+}{ }^{16}$. Se por um lado a disputa para consolidar nossa cidadania tem sido organizada em torno do nosso reconhecimento e da nossa afirmação como lésbicas, gays, travestis, bissexuais, mulheres e homens transexuais, intersexos e outras; por outro é também a denúncia do conjunto de violências exercidas contra nós contra nossas identidades sexuais e de gênero, nossos espaços e expressões - que nos aproxima. Ou seja, ao tempo em que consolidávamos contornos para disputar o

16 LGBTQI+ diz respeito a um uso mais contemporâneo da sigla que represente a aglutinação de identidades sexuais e de gênero como lésbicas, gays, bissexuais, travestis, transexuais, queers, intersexos. Algumas pessoas têm lido o "+” posto na sigla como a possibilidade de que outras identidades forjadas ao longo do processo histórico possam ser agregadas. Outras lêem o "+” como a representação de pessoas soropositivas, como forma de vencer o estigma a partir da afirmação de sua sorologia. Embora reconheçamos a importância das diferentes afirmações identitárias, seguimos ao longo do artigo utilizando o termo LGBT devido ao alcance maior que a mesma tem hoje, após a sua reorganização na I Conferência Nacional GLBT (quando se definiu que, para fins da política pública, utilizaríamos a sigla como sendo LGBT).

Vol. 01, N. 04, Out. - Dez., 2018 - www.revistas.unilab.edu.br/index.php/rebeh 
reconhecimento de um conjunto de identidades cidadãs na democracia moderna ocidental (e com elas políticas sociais e direitos civis), também nominávamos os sistemas de desigualdades (a dor) que nos atingia mais diretamente.

Estudos mais recentes aglutinaram em torno do conceito de heteronormatividade a ideia da constituição de locais diferenciados no estrato social para as identidades sexuais e de gênero. Tais locais, que tomam como referência a heterossexualidade compulsória (RICH, 2012), determinam os acessos, garantias e oportunidades da organização da vida cotidiana. Determinam ainda a forma e gestão das instituições e representações públicas e privadas. Tudo isso tomando como referência as diferentes pertenças sexuais e de gênero, interseccionadas às demais dimensões da vida social. Entendemos aqui a vida social aqui recorrendo às formulações da professora e pesquisadora Alda Britto da Motta (1999, p. 193), quando diz que "a vida social é estruturada em conjuntos de relações que, em interface, ou articuladas dinamicamente, lhe dão sentido (ou ensejam ao analista entrever um sentido...)".

A heteronormatividade, para fins analíticos, estaria no patamar de categoria estruturante das relações sociais de poder. Consideramos que o racismo, o patriarcado, o proibicionismo, o capitalismo, a heteronormatividade e outros sistemas de desigualdades sociais, estruturam de maneira desigual as diferentes dimensões sociais da vida - ora atuando mais ou menos articulados uns aos outros e sendo mais ou menos determinantes para a compreensão de recortados contextos. Cada sistema de desigualdade passou a ser compreendido a partir das epistemologias que investiram na constituição de categorias de análise. Ainda recorrendo a Motta, ela compreende que: "cada conjunto dessas categorias de análise constitui-se, então, numa dimensão básica da vida social, mas nenhuma delas, analisada isoladamente, dá conta da sua complexidade" (MOTTA, 1999, p. 193]. Seriam, portanto, categorias de análise ou dimensões básicas da vida social: classe, raça, gênero, idade, geração e, para além do considerado por Motta, a própria sexualidade. Por termos tais sistemas estruturando a vida, experimentamos a violência proporcionada pelas desigualdades atribuídas e reforçadas por eles, que são possíveis de serem sistematizadas analiticamente a partir do olhar interseccionado das diferentes categoriais criadas para este fim.

As dimensões sociais aqui são compreendidas, portanto, como lentes que nos permitem identificar a operacionalização dos sistemas de desigualdades sobre um

Vol. 01, N. 04, Out. - Dez., 2018 - www.revistas.unilab.edu.br/index.php/rebeh 
recorte de relações no tempo/espaço e com ela as relações de poder. Compreendemos como um desafio epistêmico identificar de maneira mais nítida que as dimensões sociais/categoriais de análise como a sexualidade (para compreender a operação da heteronormatividade), gênero (para o patriarcado), raça (para o racismo), drogadição (para o proibicionismo), classe (para o capitalismo) e outras podem ser acessadas de maneira isolada ou composta para lançarmos um olhar analítico mais localizado (e sempre complexo) sobre a realidade social.

Embora mudem as apreensões de cada olhar, não muda a função atribuída aqui

de tais lentes (representações das dimensões da vida social). Elas servem para lermos de maneira mais nítida como se constituíram determinadas relações sociais de poder. Mais do que isso, cumprem ainda o papel de associar o desenvolvimento de tais relações com a estruturação de diferentes sistemas sociais. Tais sistemas explicam, para nós, a construção de desigualdades (e injustiças) nas estruturas que formam a organização da vida social moderna ocidental, cotidiana de todas nós. Compreender como operam tais sistemas, em uma consideração de que são eles determinantes sociais da construção da epidemia de HIV/AIDS, nos ajuda a pensar a sua superação e com isso as diferentes estratégias no horizonte do fim da epidemia.

O feminismo negro há algum tempo já vem tratando, seja pelo conceito da natureza interligada da opressão (COLLINS, 1986:2016), da interseccionalidade (CRENSHAW, 1991) ou da multidimensionalidade (BAIRROS, 1995), a importância de compreender a vida social a partir de uma referência multifatorial, multidimensional e interligada das opressões. Entendemos aqui que é complexa a composição de diferentes dimensões da vida, mas trabalhamos aliadas as formulações do feminismo negro e da sua defesa de que é determinante instituir tal compreensão sobrepondo os reducionismos ou simplificações que frequentemente tendem a reforçar privilégios e viciar o olhar analítico (sobretudo nas produções científicas) e, com isso, a leitura e ação política mais estratégica. Interseccionalidade, multidimensionalidade ou interligação das opressões são conceitos fundamentais à apuração do olhar sobre o reconhecimento de um conjunto de violações de direitos, assim como servem ao serem acionada para a aproximação de agendas e lutas políticas. A denúncia de tais violências que sofremos em decorrência das desigualdades sociais, como já falamos, também representaram uma possibilidade de 
aglutinação de pessoas, agendas, organizações e formas de resistência social ao longo da nossa história.

Voltando a Bastos e Szwarcwald, ela e ele, assim como boa parte das formuladoras no campo dos estudos em saúde, vão nos trazer o conceito de variáveis sociais. Elas seriam determinantes encontradas no comportamento social e responsáveis por parte das alterações na ecologia de doenças como a AIDS. Ele e ela nos colocam que:

As variáveis sociais determinariam sempre alterações na ecologia das doenças infecciosas, ou seja, estratos mais pobres e menos assistidos tornam-se mais vulneráveis à difusão destes agentes por razões predominantemente biológicas (como pior imunidade), predominantemente sociais (menor capacidade de ter suas demandas atendidas, residência em locais com infraestrutura precária), no mais das vezes por razões, simultaneamente, sociais e biológicas. (BASTOS; SZWARCWALD, 2000, p. 10)

As variáveis sociais seriam o conjunto de dificuldades (desigualdades) estruturantes das vulnerabilidades às quais determinadas pessoas estariam, por diferentes motivos, sociais e biológicao, condicionadas a viver. A desassistência sempre atingiu (e segue atingindo em outras e diferentes frentes), sobretudo, populações mais empobrecidas e estigmatizadas pela ação dos diferentes sistemas de desigualdades sociais. A consequência disso foi e segue sendo um conjunto de barreiras estruturais na produção do cuidado, na construção de uma "vida saudável” (para o campo da saúde), de uma "vida digna" (para o campo dos direitos humanos), de um "bem viver" (para a luta das mulheres negras), ou como nos complementam Bastos e Szwarcwald (2000):

Perspectiva complementar à citada é a de que estes segmentos se deparam também com barreiras estruturais quanto à possibilidade de implementar e manter mudanças que minimizam os riscos de se infectar (Tawil et al., 1995). Estas barreiras são inúmeras, incluindo: indisponibilidade de recursos essenciais à prevenção (como preservativos ou seringas estéreis) devido a barreiras culturais, falta de recursos, situações de constrangimento subjetivo e objetivo de natureza diversa (a título de exemplo, pensemos na precariedade e nos riscos presentes nos locais de consumo de drogas); dificuldade de acesso a serviços de prevenção e tratamento; impossibilidade de implementar politicamente decisões comunitárias; menor escolaridade e menor domínio da linguagem escrita, o que cria obstáculos ao acesso a informações atualizadas; maiores dificuldades na manutenção de comportamentos preventivos ao longo do tempo pela pressão permanente de ameaças concretas e prementes como o desemprego, os problemas de moradia ou a fome. (BASTOS; SZWARCWALD, 2000, p. 10) 
A ABIA utiliza em suas produções o termo da "pedagogia do tratamento" para caracterizar o paradigma que atravessou e organizou os primeiros 30 anos de luta contra a AIDS. A ideia de tal pedagogia tem dentre suas criadoras (ou protagonistas) a organização Sul-africana Treatment Action Campaign (TAC), que reivindicava, no início da epidemia, o acesso de gestantes HIV-positivas aos medicamentos para prevenir a transmissão vertical (PARKER et al., 2016). Naquele momento lutava-se por acesso a profissionais de saúde que tivessem a disposição de atender um paciente em quadro de AIDS; lutava-se ainda para que medicamentos pudessem ser comercializados ou disponibilizados de maneira que as comunidades mais atingidas os acessassem; ou mesmo para que tivéssemos programas, serviços e organizações de referência para organizar o vínculo e cuidado com as pessoas infectadas ou para prevenir novas infecções.

A luta dos últimos 30 anos permitiu uma série de conquistas, avanços, criações e investidas científicas, sociais e institucionais, que não podem ser jogadas fora ou diminuídas pelas dificuldades e contradições, recuos e derrotas, com as quais elas vieram atreladas. Se hoje temos um fundo global sustentado pelos Estados-Nações, como forma de financiamento a uma resposta igualmente globalizada da epidemia, devemos a esse primeiro período de lutas e conquistas. Também devemos a esse momento a construção de uma série de ferramentas comunitárias, tecnologias sociais, assim como reinvindicações para o avanço no campo biomédico (com o desenvolvimento de medicações com menor efeito adverso e maior eficácia no controle da reprodução do vírus). A criação de éticas e técnicas de cuidado e contribuições diversas no campo da saúde coletiva são, no fundo, a nossa mais valiosa herança das primeiras lutas contra o avanço da epidemia e pelo seu fim, sendo sintetizadas pela ABIA dentro do paradigma da "pedagogia do tratamento".

Recentemente, 2016 (30 anos após a sua fundação), a ABIA apresenta em uma edição específica de seu periódico a proposta para o desenvolvimento de um novo paradigma. Ela apresenta para ser construído como forma de reaglutinação de um campo teórico e político em torno das lutas e da construção das novas estratégias pelo fim da epidemia de HIV/AIDS a "pedagogia da prevenção". Para Parker et al. (2016):

[...] a pedagogia da prevenção, segundo a definição que adotamos aqui, vai muito além da capacidade de ler. Inclui a capacidade de processar e avaliar

Vol. 01, N. 04, Out. - Dez., 2018 -www.revistas.unilab.edu.br/index.php/rebeh 
informações de saúde para tomar decisões baseadas no que é melhor para cada pessoa, de negociar e exigir o direito a essas opções e de discutir essas decisões com os parceiros e pares. A capacitação para a prevenção não significa apenas o processamento das informações, mas um processo de 'conscientização' e de empoderamento que permite às pessoas colocarem os conhecimentos em prática. (Parker et al, 2016, p. 13)

Promover o processo de "conscientização" sempre foi o papel da literatura e da organização social de diferentes agendas raciais, sexuais, de classe, gênero (para citar algumas aqui). Seriam elas determinantes da nossa capacidade de formular e escrever um novo momento da história de prevenção ao HIV/AIDS e com isso de luta pelo fim da epidemia? Apostamos aqui que o sim a essa resposta pode representar uma importante sinalização para a reaproximação entre as lutas LGBT e as contra a epidemia do HIV/AIDS.

Parker et al (2016) nos aponta que a informação processada (sobre as variadas formas de se prevenir, por exemplo), não representa necessariamente uma capacitação do sujeito para a prática da prevenção. Consideramos essa linha de raciocínio proposta por ele uma refinada forma de nos alertar sobre os desafios do próximo período e os diferentes papéis que podemos/devemos cumprir. Ao reconhecermos que as lutas e organizações sociais foram responsáveis pela capacidade de conectar (e em muitos momentos traduzir) informações e construir conhecimentos comunitários transformadores das práticas de cuidado nas comunidades mais atingidas pela epidemia de HIV, estamos vislumbrando aí (a partir do proposto por Parker) um papel que elas podem/devem cumprir na aproximação com as estratégias da Pedagogia da Prevenção.

Consideramos que uma contribuição relevante do nosso campo, assim como dos estudos e lutas feministas e raciais, está na qualificação de como somos lidas, vistas, observadas, categorizadas e reconhecidas. Neste sentido a aproximação com tal paradigma pedagógico passa também por utilizá-las para que os instrumentos que determinam os dados oficiais sobre o cenário epidêmico, e com isso a organização da ação política-institucional e os investimentos nas suas respostas, levem cada vez mais em consideração um reconhecimento sobre as epistemologias que aproximam tais ferramentas da vida cotidiana. O lugar isolado, representado pela ideia de "grupos de riscos" ou mesmo "populações-chave", que não sobrepõe (ou intersecciona) nossas vivências e práticas, pode ser um fator que tanto dificulte uma compreensão mais precisa do cenário epidêmico da AIDS, quanto opere uma desarticulação na composição dos

Vol. 01, N. 04, Out. - Dez., 2018 - www.revistas.unilab.edu.br/index.php/rebeh 
conhecimentos, estratégias e lutas em torno do seu fim. Parker et al. (2016) nos trazem uma importante reflexão sobre tais isolamentos:

\begin{abstract}
Embora os dados mostrem que [...] grupos específicos são os mais vulneráveis à transmissão do HIV, as políticas e programas raramente reconhecem a frequente sobreposição dessas categorias ou a fluidez e a troca de categorias ao longo da vida da pessoa. Na maioria das vezes, cada população-chave é discutida como se fosse separada das outras populações [...]. A realidade é que muitas pessoas podem representar, e de fato representam, uma sobreposição dessas diversas populações (que não existem isoladas umas das outras). Além dessa sobreposição, existem interfaces entre raça ou etnia, condição socioeconômica, identidade de gênero e orientação sexual que impactam as experiências sexuais e diárias de cada pessoa. Por exemplo, uma profissional do sexo que é cis e também usuária de drogas injetáveis não terá a mesma experiência sexual de uma profissional do sexo trans que também é usuária de drogas injetáveis. A sobreposição e interseção criam uma diversidade de experiências e vulnerabilidades que podem caracterizar as situações de comunidades diferentes, assim como, de pessoas diferentes, sugerindo a necessidade de um processo decisório mais elaborado e significativo em relação à complexidade das necessidades e à variedade dos métodos preventivos. (Parker et al., 2016, p. 12-13)
\end{abstract}

Acreditamos que a ampliação da nossa capacidade de fundamentar nossas existências de maneira interseccionada, multidimensionada, interligada, alteram (ao tempo em que tornam mais complexa) a apreensão das variáveis sociais consideradas determinantes sociais da epidemia. O reconhecimento mais preciso do cenário epidêmico (biológico e socialmente determinado), também orienta a forma como os investimentos econômicos, políticos e sociais serão empregados para responder a ele no curto, médio e longo prazo.

Neste ponto dos investimentos acreditamos ser necessário trazer uma polêmica questão ao centro da discussão. Ao observar as chamadas metas globais de enfrentamento a epidemia de AIDS, que estabelecem o horizonte das políticas e investimentos neste campo nos próximos 20 anos, o que temos apontado? De maneira geral a meta global visa alcançar $90 \%$ da população com HIV tendo acesso ao seu diagnóstico (entrada, testagem); $90 \%$ das que estiverem infectadas iniciando o tratamento (evolução, tratamento, medicação antirretroviral); e 90\% das que iniciarem o tratamento terem carga viral zerada/tornada indetectável (resultado) - a chamada Meta 90-90-90 é representada comumente por profissionais da saúde e ativistas pelos verbos: testar, tratar e zerar.

O foco político (e também financeiro) é deslocado para a testagem, que passa a ser vista como um direito universal ao conhecimento do estado sorológico cada vez mais cedo; segue pela ampliação do acesso ao uso das medicações antirretrovirais, Vol. 01, N. 04, Out. - Dez., 2018 - www.revistas.unilab.edu.br/index.php/rebeh 
financiadas sobretudo pelo fundo global com repasses a programas e fundos públicos e privados, garantindo o acesso de populações empobrecidas ou vulnerabilizadas ao tratamento; e é encerrada com o foco em zerar a carga viral da pessoas HIV-positivas (e com isso diminuir o risco de transmissão do vírus, considerando que pessoas com carga indetectável não transmite). Neste ponto é importante tomarmos o cuidado para no desejo de aprimorar tal perspectiva, cuja primazia biomédica é visível, não reforçarmos discursos que tentam desresponsabilizar programas e iniciativas públicas e privadas sobre a prioridade na gestão do cuidado e na disponibilização de medicamentos fundamentais para viver com o vírus do HIV. Contudo, consideramos ser também necessário refletir os impactos dessa primazia no cotidiano da organização da resposta pelo fim da epidemia.

Por exemplo, acreditamos ser importante, a partir do atual desenho das metas globais, nos perguntarmos em qual parte delas, e por isso dos investimentos e da centralidade da política global e, consequentemente, no desenho de suas respostas locais, está colocada a prevenção? Neste momento não é incomum representações do campo biomédico se levantarem para reforçar a ideia do "tratamento como prevenção" - ou seja, acessar o diagnóstico sobre sua sorologia mais cedo, iniciar o tratamento e zerar a carga viral, diminuindo as chances de transmissão, representaria para este campo a melhor estratégia, nas metas globais, de prevenção ao HIV/AIDS para o fim da sua epidemia nos próximos 20 anos.

Os dados e pesquisas biomédicas, com reconhecida notoriedade científica, não nos permitem refutar que acessar o tratamento e zerar a carga viral é uma estratégia que previne novas infecções. Contudo, acreditamos que é preciso analisar os limites desse discurso com bastante atenção e cuidado. Se por um lado é preciso reconhecer como o acesso a medicação foi determinante para desenhar um avanço da resposta global, por outro acreditamos ser arriscado creditar somente a ele (o acesso e uso da medicação para zerar a carga viral) as apostas na prevenção às novas infecções.

As nossas opiniões sobre as implicações desse desenho das metas globais na organização desse novo momento da resposta e, com isso, de uma reflexão mais aprofundada sobre as novas estratégias do movimento LGBT, não devem ser desviadas a caminhos desagregadores e por onde não nos interessam caminhar. Lutamos para ter o campo biomédico como aliado das respostas locais e globais à epidemia de AIDS e

Vol. 01, N. 04, Out. - Dez., 2018 -www.revistas.unilab.edu.br/index.php/rebeh 
seguiremos mantendo e atualizando nosso acordo ético-político de coexistência no campo das respostas a epidemia da AIDS. Contudo, quando estamos operando pela composição, recuos e avanços são importantes para se construir síntese.

\section{Conclusão - é disso que estamos falando!}

"deixa, deixa, deixa, eu dizer o que penso dessa vida preciso demais desabafar

sei que nem tudo tá certo mas com calma se ajeita

por um mundo melhor eu mantenho minha fé menos desigualdade menos tiro no pé!"

(Desabafo-Marcelo D2, 2008)

Como vimos na proposta de Parker (2016), a diversidade sexual e de gênero, assim como outros campos teórico-políticos podem cumprir, nesse momento, um importante papel na recomposição da resposta a epidemia de HIV por meio da Pedagogia da Prevenção. Somos nós, estudiosas e militantes desses diferentes campos, quem melhor podemos qualificar tanto a aproximação com as populações vistas hoje como mais vulnerabilizadas e por isso em maior risco às novas infecções, quanto a aglutinação de força social e política necessária para a disputar os instrumentos de composição de dados sobre o cenário epidêmico e com isso de definição do financiamento global e local - das prioridades dos investimentos - para o fim da epidemia. Para nós, está aí a possibilidade de amarrar uma consequente aliança entre o fervo, a diversidade sexual e de gênero e a pedagogia da prevenção.

Explico: o fervo, identificado como sendo um emergente conjunto de deslocamentos e de novas formas de participação democrática produzidas em torno da organização de festividades urbanas politicamente engajadas, e sendo reivindicado como um contexto cujo protagonismo é exercido na organização e na participação por jovens negras(os), mulheres e LGBT, de periferia, com idades em 20-24 anos, nos parece ser um emergente local para experimentarmos a constituição da aliança entre novos Vol. 01, N. 04, Out. - Dez., 2018 - www.revistas.unilab.edu.br/index.php/rebeh 
protagonistas das lutas por liberdade sexuais e de gênero e as estratégias da pedagogia da prevenção.

$\mathrm{Na}$ etnografia construída no trabalho de conclusão de curso, pude aplicar um questionário na primeira edição da festa Afrobapho realizada em abril de 2016 na cidade de Salvador. A festa contou com pouco mais de 300 participantes e 35 delas responderam ao instrumento da pesquisa, que era ofertado juntamente com a ação do Coletivo Kiu! na área de convivência da festa. Aproximadamente 37\% das participantes que colaboraram com o estudo tinham idades entre 18-20 anos; outros 40\% tinham idades entre 21-24 anos; somados, esses dados nos sugerem que cerca de $77 \%$ das participantes da festa tinham idades entre 18-24 anos.

Segundo os dados do Boletim Epidemiológico o vetor das novas infecções pelo HIV no Brasil, triplicou entre pessoas de 15-19 anos e duplicou entre 20-24 anos ${ }^{17}$. A forte presença de jovens com idades que tangenciam esses dois grupos na festa Afrobapho nos sugeriram ser este contexto um emergente local para a construção de parceiras que tenham como horizonte a estruturação das novas respostas comunitárias à epidemia do HIV/AIDS. Apostamos aí que o fervo é, assim como MacRae apostou nos anos 1970 no gueto, uma cena privilegiada para pensar a prevenção combinada à epidemia do HIV/AIDS no Brasil, numa perceptiva que leve em conta o fortalecimento do paradigma da Pedagogia da Prevenção.

O que tem sido chamado de "prevenção combinada" é uma importante questão a ser fortalecida por estes campos e setores da academia ou do fervo. A ideia de promoção da "prevenção combinada", segundo a ABIA, surge a partir da proposição de organizações globais engajadas na resposta ao HIV (Parker et. al., 2016, p. 3). Supomos aqui que ela surge, ainda, com uma função de reparar, em nível local e global, a ausência da dimensão da prevenção dentre as metas expressas para os investimentos nos próximos 20 anos. A prevenção combinada passa por compor diferentes estratégias "biomédicas, comportamentais e estruturais (idem) e tentam reconhecer o papel fundamental de um amplo e já disponível conjunto de estratégias preventivas para erradicar a AIDS" (ibidem). Ela serve, portanto, para não acabar perdendo o que já

\footnotetext{
${ }^{17}$ Além dos Boletins Epidemiológicos já referenciados neste artigo, tal informação circulou na mídia nacional como é possível ser visto na matéria de O Globo, datada de 07/06/2018, disponível em < https://oglobo.globo.com/sociedade/casos-de-hiv-entre-jovens-gays-de-15-19-anos-triplicam-em-dezanos-22754758 >, acessada em 28 de novembro de 2018.
}

Vol. 01, N. 04, Out. - Dez., 2018 - www.revistas.unilab.edu.br/index.php/rebeh 
conquistamos com as experiências exitosas seja do campo biomédico ou comunitário, representando hoje a nossa melhor e mais madura síntese.

Voltando um pouco a ideia da "pedagogia do tratamento", ela representou o momento em que lutávamos justamente pelo acesso mais universal a medicações de ponta, serviços de tratamento e outras tecnologias e estruturas fundamentais para acolher e cuidar das pessoas HIV-positivas. Como aponta Parker et al. (2016),

\footnotetext{
A ampliação do fornecimento de antirretrovirais foi acompanhada da necessidade crescente de um entendimento mais aprofundado e de maior poder de decisão em relação ao tratamento. Como resultado, grupos de ativistas de AIDS promoveram a pedagogia do tratamento (PARKER et al., 2016, p. 4-5).
}

Ao tempo em que reivindicávamos a ampliação do fornecimento de medicações, propusemos "a pedagogia do tratamento de maneira que associa a medicina à política, aos direitos humanos, à igualdade e aos deveres do governo" (PARKER et al, 2016, p. 45). Com isso, responsabilizávamos governos, serviços e gestores de saúde e exigíamos deles as condições necessárias para "transformar as pessoas HIV-positivas em donas de seu próprio tratamento" (idem). Esse processo passava por garantir os "meios para documentar a maneira pela qual os contextos sociais, a violência e a própria doença afetam as pessoas vivendo com HIV" (ibidem), mas também os investimentos necessários para uma efetiva e qualificada participação dessas pessoas no controle social dos recursos e da própria formulação das prioridades políticas para responder à epidemia.

Em outras palavras, as ações de advocacy junto as institucionalidades locais e internacionais visando mediar o acesso das comunidades mais desassistidas a orientação, serviços e também medicações; assim como organizar o controle social sobre os investimentos destinados a resposta da epidemia, a luta por uma maior transparência dos governos na aplicação desses recursos; a disputa por condições para que as comunidades mais atingidas tivessem um maior controle na construção do seu tratamento, etc, foram funções assumidas por organizações comunitárias a partir e no período do desenvolvimento da chamada pedagogia do tratamento.

Os investimentos locais e internacionais direcionados a manutenção de tais ações foram responsáveis pelo financiamento de uma série de grupos LGBT e/ou organizadores das comunidades mais atingidas durante muitos anos. A luta pela Vol. 01, N. 04, Out. - Dez., 2018 - www.revistas.unilab.edu.br/index.php/rebeh 
ampliação do acesso global a medicamentos nos pareceu possível, dentre outros elementos, devido a existência de sólidas bases e organizações comunitária, financiadas para incidir nas instâncias locais e internacionais, visando, assim, pautar a responsabilidade de governos e estruturas políticas com o tratamento e a vida das pessoas HIV-positivas (PARKER et al., 2016).

Estas mesmas organizações comunitárias foram as responsáveis, em muitos casos e durante um longo período, pelo primeiro acolhimento e orientação das pessoas recém infectadas, assim como do seu consequente encaminhamento para os serviços públicos de saúde (que mais à frente tornam-se serviços específicos de HIV/AIDS e outras ISTs dentro da rede pública de saúde), onde a testagem e/ou tratamento poderiam ser acessados. Ou seja, tais organizações serviram de modelo para a construção hoje de uma rede de serviços públicos de cuidado e atenção ao tratamento do HIV e outras Infecções Sexualmente Transmissíveis (ISTs)

Foram, ainda, essas organizações as que desenvolveram inúmeras ações, éticas, técnicas e tecnologias de prevenção, por meio da informação, das rodas de diálogo entre pares, da presença em variados contextos e espaços, ou mesmo na organização e afirmação social de diferentes identidades políticas cidadãs que ao enfrentar as desigualdades estruturantes auxiliam com isso na diminuição do risco das novas infecções.

Com o fim dos investimentos nas organizações sociais, temos presenciado uma desarticulação e desestruturação hoje, incluindo aí todas as organizações LGBT mais tradicionais do país, no controle social e na transparência da aplicação dos recursos que chegam ou que são reservados nos orçamentos locais para financiar a resposta à epidemia. Tais recursos visam atender as metas globais e de maneira geral tornam-se “carimbados” para aquisição de testagem ou de medicações antirretrovirais - além das profilaxias pós exposição (PEP) e, no Brasil, mais recentemente no serviço público, da profilaxia pré-exposição (PrEP). Em alguns estados, a consequência disso tem sido a diminuição ou o encerramento de editais para seguir com o apoio ao trabalho de organizações de base comunitárias, fundadas no primeiro momento de resposta à epidemia, criando assim uma descontinuidade nas estratégias de cuidado oriundas de tais grupos e desorganizando sua função determinante na resposta pelo fim da epidemia.

Vol. 01, N. 04, Out. - Dez., 2018 - www.revistas.unilab.edu.br/index.php/rebeh 
Ao mesmo tempo, não vislumbramos nenhuma perspectiva que envolva o financiamento de coletivos ou coletividades como as que protagonizam as festividades do fervo. Ou seja, por maior que seja a potencialidade de tais contextos, construídos por esses novos agrupamentos, que têm como protagonistas jovens com idades entre 18-24 anos, negras(os), mulheres e LGBT, de periferia, na reconstrução de uma resposta comunitária à epidemia, não há perspectiva nas metas globais e muito menos nos financiamentos locais que considerem tais coletivos e coletividades como centrais para o próximo período de resposta as novas infecções.

O fechamento de inúmeras organizações comunitárias, fundadas para organizar as primeiras respostas à epidemia, ou as dificuldades de manter suas portas abertas e o seu trabalho de conscientização (sobre o reconhecimento e afirmação de uma identidade política cidadã ou mesmo, como é possível pensar a partir da proposta de Parker, da construção de uma prática preventiva) sendo realizado, nos parece ser a consequência mais grave até aqui da falta de tato ou consideração das metas e investimentos globais e locais com as estratégias que pensam o fim da epidemia levando em consideração as pessoas mais expostas, em decorrência das desigualdades sociais, às novas infecções. Esse desmonte nos investimentos às organizações sociais e consequentemente às alianças com outras lutas e agendas, concretamente, agravam ainda mais o avanço da epidemia e poderiam ser objeto de maior atenção de estudos e esforços sociais e institucionais com vistas a sua urgente correção e ajuste.

O fervo e seus coletivos e coletividades nos pareceram uma atuante e potente forma de organização comunitária a ser reconhecida e aproximada considerando que seu contexto aglutina hoje as pessoas em maior risco de novas infecções no país. Em tempos onde falta financiamento para que o trabalho dos tradicionais grupos LGBT seja feito, a aproximação com elas e eles nos parece ser um emergente fator a ser considerado nos desenhos das estratégias que se somam pelo fim da epidemia de HIV/AIDS no Brasil. Não podemos perder de vista que só com força social construiremos condições de disputar um novo rumo das respostas e (por que não?) dos investimentos globais e locais pelo fim da epidemia. A força social do fervo é comprovada hoje pelo seu público. Coletivos e festas como a Batekoo, existem hoje em mais de 5 capitais, com uma agenda mensal regular e a mobilização de inúmeras jovens. Assim como ela, outras coletividades e festas, igualmente engajadas na superação de opressões sociais, têm se

Vol. 01, N. 04, Out. - Dez., 2018 -www.revistas.unilab.edu.br/index.php/rebeh 
proliferado pelas mais diferentes cidades do país. Um mapeamento de tais deslocamentos nos parecem ser um elemento que não pode mais passar ao lado das respostas produzidas sejam pelos estudos ou organizações mais tradicionais do movimento LGBT ou do movimento AIDS. É emergente, no sentido da urgência e do surgimento, a constituição de pontes e diálogos com esses contextos e a consolidação de alianças estratégicas com os mesmos.

Buscamos, portanto, com esse artigo sistematizar elementos que nos permitissem aproximar o fervo, o campo da diversidade sexual e de gênero e a pedagogia da

prevenção com o objetivo de: (1) reconhecer a potência organizacional e cuidadora de coletivos e coletividades organizadoras de festas urbanas politicamente engajadas; (2) pensar como tais coletividades, ao serem reconhecidas pelo diferentes campos e lutas, podem ser importantes interlocutoras da recomposição das respostas comunitárias e na construção de práticas preventivas baseadas na "pedagogia da prevenção" e nas estratégias de "prevenção combinada"; (3) reaproximar o interesse dos estudos e lutas LGBT no país com o fim da epidemia de HIV/AIDS, mas também com os estudos de festas; acreditando que desta maneira podemos (4) contribuir com a construção de um bloco social interseccional, multidimensional, interligado, capaz de qualificar novas estratégias de luta contra as opressões sociais no Brasil e no mundo, e com elas reconhecer novas formas de participação democrática; aproximando, assim as (tradicionais e novas) protagonistas das lutas e movimentos LGBT das metas que desejam o fim da epidemia de HIV/AIDS, mas também contribuindo para a consolidação de uma resistência democrática que incida estruturalmente na desconstrução das desigualdades sociais e reconstrução do horizonte digno e de bem viver.

\section{Referências}

BASTOS, Francisco Inácio; SZWARCWALD, Célia Landmann. AIDS e pauperização: principais conceitos e evidências empíricas. In: Cad. Saúde Pública [online], vol.16, suppl.1. Rio de Janeiro. FIOCRUZ. 2000. p. 65-76. Disponível em < http://www.scielo.br/pdf/\%0D/csp/v16s1/2213.pdf $>$. Acesso em 28 de novembro de 2018.

BRASIL, República Federativa do. Boletim Epidemiológico - Aids e DST-Ano V - no 1 - 01a à 26a semanas epidemiológicas - janeiro a junho 2017. In: Secretaria de Vigilância

Vol. 01, N. 04, Out. - Dez., 2018 - www.revistas.unilab.edu.br/index.php/rebeh 
em Saúde - Departamento de Vigilância, Prevenção e Controle das Infecções

Sexualmente Transmissíveis, editors. Brasília. Ministério da Saúde. 2017.

BAIRROS, Luiza. Nossos feminismos revisitados. In: Revista Estudos Feministas, $\mathrm{n}^{\circ}$ 02. Santa Catarina. UFSC. 1995. p. 458-463. Disponível em <

https://www.geledes.org.br/wp-

content/uploads/2014/04/Nossos_Feminismos_Revisitados_Luiza_Bairros.pdf $>$. Acesso em 28 de novembro de 2018.

COLLINS, Patricia Hill. Aprendendo com a outsider within*: a significação sociológica do pensamento feminista negro. In: Revista Sociedade e Estado [online], vol. 31, $\mathrm{n}^{\circ} 01$. Jan/Abril. 2016. p. 99-127. Disponível em < http://www.scielo.br/pdf/se/v31n1/01026992-se-31-01-00099.pdf >. Acesso em 28 de novembro de 2018.

DUSSEL, Enrique. 20 Teses de política. $1^{\mathrm{a}}$ ed. Buenos Aires. Consejo Latinoamericano de Ciencias Sociales (CLACSO). São Paulo. Expressão Popular. 2007.

GUIMARÃES, Marcelo; MACRAE, Edward; ALVES, Wagner. Coletivo balance de redução de riscos e danos: ações globais em festas e festivais de música eletrônica no Brasil (2006-2010). In: FILHO, Antonio Nery; MACRAE, Edward; TAVARES, Luiz Alberto; RÊGO, Marlize; NUÑEZ, Maria Eugênia. As drogas na contemporaneidade: perspectivas clínicas e culturais. Salvador. EDUFBA. 2012. P. 101-122. Disponível em $<$

http://www.repositorio.ufba.br:8080/ri/bitstream/ri/7895/1/As_drogas_na_contemporane idade_RI.pdf >. Acesso em 28 de novembro de 2018.

MACRAE, Edward. A construção da igualdade: Identidade Sexual e Política no Brasil da "Abertura". Campinas. Editora da UNICAMP. 1990.

. Movimentos Sociais e os Direitos de Cidadania dos Homossexuais. In: ARAÚJO, A. (Org.). Trabalho, cultura e cidadania - um balanço da história social brasileira. São Paulo. Editora Scrittta. 1997. pp. 237-242.

. Os respeitáveis militantes e as bichas loucas. In: MACRAE, E. et al (Orgs.). Caminhos Cruzados - Linguagem, Antropologia e Ciências Naturais. São Paulo. Editora Brasiliense. 1982. pp. 99-111.

. Em Defesa do Gueto. In: Novos Estudos CEBRAP. Vol. 2, nº 1, abril de 1983. São Paulo. CEBRAP. 2013. pp. 53-60.

MORAES, Alana; GUTIÉRREZ, Bernardo; PARRA, Henrique; ALBUQUERQUE, Hugo; TIBLE, Jean; SCHAVELZON, Salvador. Junho está sendo. In: Idem (Org). JUNHO potência das ruas e das redes. São Paulo. Fundação Friedrich Ebert Stiftung (FES). 2014.

MORAS, Alana; TIBLE, Jean. Quando novos personagens entram em cena? In: MORAES, Alana; TARIN, Bruno; TIBLE, Jean (Org). Cartografias da Emergência:

Vol. 01, N. 04, Out. - Dez., 2018 - www.revistas.unilab.edu.br/index.php/rebeh 
novas lutas no Brasil. São Paulo. Fundação Friedrich Ebert Stiftung (FES). 2015. p. 1439.

MOTTA, Alda Britto da. As dimensões de gênero e classe social na análise do envelhecimento. In: Cadernos de Pagu (13). Campinas. UNICAMP. 1999. p. 191-221.

MOUFFE, Chantal. Democracia, cidadania e a questão do pluralismo. In: Revista Política \& Sociedade. N ${ }^{\circ}$ 3. Programa de Pós-Graduação em Sociologia Política da Universidade Federal de Santa Catarina. Santa Catarina. 2003. p. 11-26. Disponível em < https://periodicos.ufsc.br/index.php/politica/article/viewFile/2015/1763 > Acesso 28 de novembro de 2018.

PARKER, Richard. Sobre a história da ABIA e a resposta brasileira frente à AIDS. In: Brasil. Ministério da Saúde. Secretaria de Vigilância em Saúde. Departamento de DST, AIDS e Hepatites Virais. História de luta contra a AIDS. Brasília. Ministério da Saúde. . 2015. p. 24-31

GAVIGAN, Kelly; RAMIREZ, Ana; MILNOR, Jack; PEREZ-BRUMER, Amaya; TERTO JR, Veriano; PARKER, Richard. Pedagogia da Prevenção: Reinventando a prevenção do HIV no século XXI. In: Observatório Global / Observatório Nacional de Políticas de AIDS (Org). Perspectiva e Política. Novembro 2015. Rio de Janeiro. ABIA. 2015. Disponível em < http://abiaids.org.br/wpcontent/uploads/2015/11/PolicyBrief_portugues_jan2016.pdf $>$. Acesso em $28 \mathrm{de}$ novembro de 2018.

PEREIRA, Carlos Alberto M.. O que é contracultura?. São Paulo. Brasiliense. 1983.

Perez, Léa Freitas.. Dionísio nos trópicos: festa religiosa e barroquização do mundo por uma antropologia das efervescências coletivas. In: Mauro Passos. (Org.). A festa na vida: significado e imagens. 1ed. Petrópolis. Vozes. 2002. p. 15-58.

RACE, Kane. Pleasure consuming medicine. The queer politics of drugs. Nova York. Duke University Press. 2009.

Party Animals: The significance of drug practices in the materialization of urban gay identity. In: S. Fraser \& D. Moore (eds.) The Drug Effect: Health, Crime \& Society. Cambridge University Press. Melbourne. Cambridge University Press. 2011.

JÚNIOR, Antônio Carlos Ribeiro. O antiproibicionismo de Salvador/BA: uma análise de suas características, organização, trajetórias e projetos entre 2013 e 2016. Salvador. 2017

RICH, A. Heterossexualidade compulsória e existência lésbica. Bagoas - Estudos gays: gêneros e sexualidades, v. 4, n. 05, 27 nov. 2012. Disponível em < https://periodicos.ufrn.br/bagoas/article/view/2309 > Acesso em 28 de novembro de 2018.

SARDENBERG, Cecília. Caleidoscópios de gênero: Gênero e interseccionalidades na dinâmica das relações sociais. In: Dossiê - Desigualdades e Interseccionalidades. 2015.

Vol. 01, N. 04, Out. - Dez., 2018 - www.revistas.unilab.edu.br/index.php/rebeh 
Disponível em <

http://www.uel.br/revistas/uel/index.php/mediacoes/article/download/24125/Caleidosc\% C3\%B3pios\%20de\%20g\%C3\%AAnero >. Acesso em 01 de Maio de 2016.

SILVA, Ariel Lucas; MIGUEZ, Paulo. Cultura, Festa e Cidade: tecendo relações. In: Revist@ Observatório da Diversidade Cultural, Vol. 1, n 1. Belo Horizonte. 2014. Disponível em < http://www.observatoriodadiversidade.org.br/revista/edicao_001/Revista-ODC-001$\underline{02 . p d f}>$. Acesso em 01 de Maio de 2016.

WELLER, Wivian. A atualidade do conceito de geração de Karl Mannheim. In: Revista Sociedade e Estado, $\mathrm{n}^{\circ}$ 25, Volume 2. Brasília. 2010. Disponível em < http://www.scielo.br/scielo.php?script=sci_arttext\&pid=S0102-69922010000200004 >. Acesso em 28 de novembro de 2018.

\title{
The Fervo, Sexual and Gender Diversity and a Pedagogy of Prevention
}

\begin{abstract}
This article presents a dialogue between HIV/AIDS research and the theoretical-political field of sexual and gender diversity. I use as an element for such reflection the ethnographic study conducted for the conclusion of the Bachelor in Gender and Diversity Studies called "In Defense of the Fervo: ethnographic views on the emergence of care production in the context of urban parties in Salvador-BahiaBrazil". This is relevant to contribute towards the recomposition of LGBTI+ studies and struggles in the country and the other historical field that built the studies and responses to the AIDS epidemic in the late 1980s and early 1990s (especially its potent community current). However, I believe that this rapprochement should occur with updating our eyes and recognition of new forms of political organization and social protest. I defend the boil as a privileged context for this, because it is carried out by young, black, women and LGBT people from the periphery. The group of collectives organizing politically engaged urban parties (which I call Fervo), today demonstrate to us an organizational potential and emergente (in the sense of urgency and emergence) caretaker. We argue that their recognition (of them) can help in the process of reflection and oxygenation of our strategies in the LGBTI+ movement in Brazil. In the same vein, they can also strengthen what has been pointed out in ABIA's recent productions, and its CEO Richard Parker, about the so-called "pedagogy of prevention" - a new social paradigm proposed by the entity to organize the response to the epidemic. We propose here the opening of some reflections involving the boiling, the sexual and gender diversity and the pedagogy of prevention.
\end{abstract}

Keywords: Party; Caution; LGBTQI + Fights; HIV/AIDS; Sexual and Gender Diversity.

Recebido em: 09/09/2018

Aceito em: 23/11/2018

Vol. 01, N. 04, Out. - Dez., 2018 - www.revistas.unilab.edu.br/index.php/rebeh 